\title{
"BRASILEIRO DE MEIA COR E MEIA CLASSE": A VIDA DE GONÇALVES DIAS POR LÚCIA MIGUEL PEREIRA
}

\section{"A HALF COLORED AND HALF CLASS BRAZILIAN": THE LIFE OF GONÇALVES DIAS BY LÚCIA MIGUEL PEREIRA"}

\author{
Andréa Camila de Faria Fernandes ${ }^{1}$ \\ Marcia de Almeida Gonçalves ${ }^{2}$
}

\section{RESUMO}

Ao longo das décadas de 1920 a 1950, na sociedade brasileira, a escrita biográfica adquiriu novas formas e funções entre intelectuais, editores, empreendedores do mundo dos livros e leitores. Assistiu-se à significativa proliferação editorial de biografias, fato que foi acompanhado pelo debate acerca da emergência da biografia moderna em terras brasileiras. $O$ debate não se configurou apenas como a problematização de uma nova biografia, foi também, para alguns intelectuais, a perspectiva de redimensionar a escrita da história nacional. Nesse sentido, se a história, enquanto conhecimento disciplinar era, por excelência, um instrumento basilar na configuração da identidade nacional, a discussão de como ela deveria ser escrita, e de que sujeitos deveriam protagonizá-la, acabava por cruzar com o debate sobre a emergência de uma nova biografia, na delimitação de quem de fato construíra ou havia construído para edificação da nação, suas singularidades políticas e referências culturais. Entre os autores que estiveram envolvidos com essas questões, destacamos Lúcia Miguel Pereira. Autora de biografia de Machado de Assis e de Gonçalves Dias, Lúcia Miguel Pereira desenvolveu trabalhos onde buscava "fazer viver" seu biografado, apresentando-os como sujeitos imersos nas incertezas das circunstâncias históricas. Para a autora, a biografia era o melhor meio de se fazer história, pois, em função de determinados recursos retóricos, produziria efeitos sensibilizadores sobre seus leitores, tornando os brasileiros mais interessados pelas grandes figuras de sua terra. Lucia Miguel Pereira buscava na biografia o que julgava faltar no ensaio histórico e entendia que o hibridismo das biografias modernas, "nem romance nem história", instituía o equilíbrio necessário e sedutor. Nesse artigo analisaremos a biografia "A vida de Gonçalves Dias”, publicada por Lúcia Miguel Pereira em 1943, entendendo que esse texto possibilita não apenas investigar um novo modelo de escrita biográfica, mas também analisar os processos de canonização e de construção das imagens de Gonçalves Dias associadas à galeria dos "brasileiros ideais".

Palavras-chave: Biografia Moderna. Identidade Nacional. Gonçalves Dias.

\footnotetext{
1 Mestre em História pelo PPGH/UERJ, bolsista FAPERJ do NUBHES/UERJ (Núcleo de Estudos sobre Biografia, História, Ensino e Subjetividades). Rio de Janeiro / Brasil. andreacamila@oi.com.br

2 Professora Adjunta da UERJ. Doutora em História Social pela FFLCH/USP. Rio de Janeiro / Brasil. agmarcia@uol.com.br
} 


\begin{abstract}
During the decades of 1920 until the fifties', in Brazilian society, biographical writing acquired new forms and functions among intellectuals, publishers and readers. The significant editorial proliferation of biographies was accompanied by the debate about the emergence of modern biography. The debate is not configured just as the questioning of a new biography; it was also, to some intellectuals, the prospect of giving new meanings to the writing of national history. In this sense, history, as an academic and disciplinary knowledge was, par excellence, a fundamental instrument in the national identity configuration. The discussion of how history should be written crossed the debate about the emergence of a new biography. A new history and a new biography would redefine the choice of who indeed built or had contributed for nation building, its political singularities and cultural references. Lucia Miguel Pereira was one of the authors who had been involved with these issues. At that time, she wrote Machado de Assis' biography and Gonçalves Dias' biography. Lucia Miguel Pereira developed her biographical work in order to "make live" those characters, presenting them as individuals immersed in unexpected historical circumstances. For Lucia Miguel Pereira, the biography was the best way to make history because, in terms of certain rhetorical devices, it would produce sensitizing effects on the readers, making Brazilians more interested by the great figures of their land. Lucia Miguel Pereira had understood modern biography as a manner of rethinking the historical essay, a kind of hybrid text, novel and history at the same time. In this article we will analyse the biography "Life of Gonçalves Dias", published by Lucia Miguel Pereira in 1943. In our understanding, this text provides not only an investigation about a new biographical writing style, but also permits the interpretation of the processes of canonization and construction of Gonçalves Dias' images, associated with the gallery of the "ideal Brazilians."
\end{abstract}

Keywords: Modern Biography. National Identity. Gonçalves Dias. 
Quem quer que for bom historiador deve ser uma destas duas coisas: ser político ou poeta.

Gonçalves Dias

\section{Entre textos e contextos}

No decorrer da primeira metade do século XX, a escrita biográfica passou a usufruir de significados e usos alargados entre intelectuais, empreendedores do mundo dos livros e seus respectivos leitores. No Brasil, a significativa proliferação editorial de biografias, entre os anos de 1930-1950, especialmente, fez com que alguns teorizassem sobre a emergência do que então foi denominado de biografia moderna. Debate extenso e controverso, como procuraremos situar ao longo desse artigo, significou também, para alguns intelectuais, a perspectiva de redimensionar a própria escrita da história nacional e, em estreita correspondência, as análises sobre a história da literatura brasileira, em um movimento de redescobrimento e de reinvenção das referências identitárias brasileiras.

Nesse sentido, se a história, enquanto conhecimento disciplinar era, por excelência, um instrumento basilar na edificação da identidade nacional, a discussão sobre como ela deveria ser escrita, e sobre que sujeitos deveriam protagonizá-la e agenciá-la - os indivíduos, os grupos, as forças sociais - sobrepunha-se ao debate sobre quem de fato construíra ou havia construído a nação. Nesse cruzamento tenso, o lugar do texto biográfico era buscado e, por vezes, entendido como a panaceia que poderia resolver tantos impasses.

Entre os autores que estiveram envolvidos com esses debates e questões no Brasil, naquela época, interessa-nos recuperar a crítica literária e escritora Lúcia Miguel Pereira. Nascida em Barbacena, em 12 de dezembro de 1901, a segunda, entre os seis filhos do médico Miguel da Silva Pereira e de Maria Clara Tolentino Pereira, Lúcia Miguel Pereira, em tenra idade, veio viver na cidade do Rio de Janeiro, realizando seus estudos no Colégio Notre Dame de Sion (PEREIRA, 1988a, p.11).

O primeiro romance, "Maria Luísa", veio a público em 1933, pela editora de Augusto Frederico Schmidt. No mesmo ano, outro texto de 
sua autoria chegava aos leitores, "Em surdina", sob os cuidados editoriais de Gastão Cruls e Agripino Grieco, ambos responsáveis pela criação do "Boletim de Ariel” (1931-1938), mensário crítico-literário no qual Lúcia Miguel Pereira tornou-se assídua colaboradora.

Outros romances vieram a ser publicados - "Amanhecer" (1938) e "Cabra-cega" (1954), ambos pela José Olympio -, além de livros infanto-juvenis - "A Fada Menina" (1939), "A Filha do Rio Verde" (1943), “A Floresta Mágica” (1943), "Maria e seus Bonecos” (1943). O maior reconhecimento de nossa escritora, entre contemporâneos e pares, esteve associado à crítica e à história da literatura, fosse pela colaboração regular para diversos periódicos, como a "Gazeta de Notícias", a "Revista do Brasil", na sua terceira fase (1938-1943), o já mencionado "Boletim de Ariel", o "Correio da Manhã" e o "Estado de São Paulo"; fosse pela publicação, em 1943, de "A vida de Gonçalves Dias" e de "Prosa de Ficção" (1870-1920), em 1950, ambos pela José Olympio (PEREIRA, 1988a, p. 11-14).

Casada, a partir de 1940, com Octávio Tarquínio de Sousa, moradora do Rio de Janeiro, sua residência foi, até a morte de ambos, em acidente aéreo, em dezembro de 1959, ponto de encontro para um conjunto de amigos - Manuel Bandeira, Sérgio Buarque de Holanda, Carlos Drummond de Andrade, José Américo de Almeida, Álvaro Lins, Rachel de Queiroz -, entre outros diletos representantes do mundo da produção letrada (PEREIRA, 1992, p. XII-XX).

Lúcia Miguel Pereira, nas biografias que produziu, buscou "fazer viver" os biografados, apresentando-os como sujeitos imersos nas incertezas das circunstâncias sócio-históricas. Para a autora, a biografia era o melhor meio de se fazer/escrever história, pois, em função de determinados recursos retóricos, produziria efeitos sensibilizadores sobre seus leitores, tornando os brasileiros mais interessados pelas grandes figuras de sua terra. Lucia Miguel Pereira entendia a biografia como uma forma de conhecimento rica em determinadas possibilidades interpretativas que julgava faltar ao ensaio histórico. Especialmente, no caso das biografias modernas, seu o hibridismo "nem romance nem história" - poderia instituir, para os leitores, o equilíbrio necessário e sedutor entre erudição, pesquisa documental e criação literária. 


\section{Em debate: a biografia}

Nesse posicionamento particular acerca da biografia moderna, Lucia Miguel Pereira demonstrava estar a par do debate que então ocorria sobre as mudanças que afetaram a escrita de histórias de vida. Em finais da década de 1920, Alceu Amoroso Lima, em artigo sobre textos biográficos e autobiográficos recém lançados, diagnosticava a existência de uma "verdadeira epidemia biográfica" (LIMA, 1931, p. 165-177).

$\mathrm{O}$ autor percebera, por um lado, o crescimento quantitativo da publicação de biografias e de outros textos afins - autobiografias, memórias -, todos, em alguma medida, situados no campo largo de narrativas e/ou ensaios centrados em trajetórias individuais de vida. Por outro lado, a verificação do crescimento quantitativo de textos dessa natureza era associada a mudanças qualitativas. Como destacou Alceu Amoroso Lima, a onda epidêmica de publicações biográficas, autobiográficas e memorialísticas era o sinal da emergência do novo, leia-se, o moderno, nesses gêneros de produção textual (LIMA, 1931).

Alceu Amoroso Lima e outros contemporâneos, Gastão Cruls, Luís Vianna Filho, Edgard Cavalheiro, Álvaro Lins, cada um à sua maneira, refletiram sobre o que passou a ser denominado de biografia moderna e/ou romanceada, explicitando, em muitas de suas ponderações, novas formas e funções para essas narrativas. A discussão, como assinalaram seus promotores, era o sintoma de mudanças éticas e estéticas, fosse na própria concepção de sujeito individual, fosse nas maneiras de representá-lo, em particular entre os materiais da criação artística e literária (GONÇALVES, 2009a).

Como diagnosticara Alceu de Amoroso Lima ${ }^{3}$, a biografia tornara-se no inicio do século XX o gênero literário que realizara, a despeito das controvérsias, a ligação entre o romance e a história. Nas suas palavras:

${ }^{3}$ O crítico Alceu Amoroso Lima também era conhecido pelo pseudônimo de Tristão de Ataíde, daí a referencia que se segue, da citação retirada do livro de Luiz Vianna Filho. 
Como a biografia é exatamente o gênero literário que faz o traço de união entre o romance e a história - sem ter a realidade fantasista de um, nem a erudição rebarbativa do outro - foi ele talvez o gênero que mais se desenvolveu modernamente, desde que Michelet aproximou a história do romance e Proust o romance da história (ATAÍDE apud VIANA FILHO, 1945, p. 24).

Críticos e autores brasileiros dialogaram diretamente, com maior ou menor originalidade, com intelectuais europeus, cujas obras vieram a ser eleitas como matrizes da renovação do gênero biográfico. André Maurois (1885-1967), na França, Emil Ludwig (1881-1948), na Alemanha, e Lytton Strachey (1880-1932), na Inglaterra, foram os autores emblemáticos de biografias onde homens e mulheres desciam de seus panteões de notáveis para personificar a grandeza e a miséria de suas condições humanas. Cada um deles, donos de estilos próprios e diferenciados, personificaram, com direito a polêmicas, os arautos de uma escrita biográfica que se queria moderna. Todos, em seus países de origem, e nas traduções de suas principais obras, alcançaram sucesso editorial e reconhecimento internacional como renovadores de um gênero que, segundo alguns, havia sido engolfado pelos panegíricos oficiais de memórias nacionalistas. As poéticas do elogio de literatos e dirigentes políticos, tão caras a um imaginário oitocentista, passaram a ser lidas como a tradição de uma escrita biográfica que, nos seus resultados, nada mais fizera do que elaborar a coleção de estátuas de bronze ou mármore de notáveis da pátria (GONÇALVES, 2009a, 2009b). No ambiente letrado brasileiro, dois nomes despontaram nesse gênero, o de Lúcia Miguel Pereira e o de Otávio Tarquínio de Souza ${ }^{4}$, seu marido desde 1940.

Daniel Madelénat, em sua obra referencial La biographie, ao analisar a biografia moderna, argumenta que o surgimento desta forma de escrita biográfica esteve associado à crise dos valores do humanismo grecolatino, da religião cristã e dos racionalismos e ao desenvolvimento e a difusão das filosofias do inconsciente, das teorias freudianas, das revisões do cientificismo positivista e dos variados modernismos, em especial nas artes, no alvorecer do século XX. Nesse momento, segundo o autor, ampliou-se a concepção da biografia como gênero

${ }^{4}$ Octávio Tarquínio de Sousa foi autor das biografias reunidas na coleção História dos fundadores do Império do Brasil. Para maiores informações sobre sua vida e sua obra ver: GONÇALVES, 2009, 2011a e 2011b. 
híbrido, junção criativa da história e do romance (MADELÉNAT, 1984).

Tal concepção foi consideravelmente debatida entre críticos e literatos ingleses, orientando a produção intelectual de autores como Harold Nicolson, Lytton Strachey e Virginia Woolf, integrantes do que veio a ser conhecido como o Bloomsbury Group. O nome de um bairro de Londres tornou-se a designação de um grupo de amigos que estudaram em Cambridge, no Trinity ou no King's College, compondo um círculo de escritores, intelectuais e artistas, do qual participaram Leonard Woolf, Arthur Waley, Clive e Vanessa Bell, irmã de Virgínia, Roger Fry, John Maynard Keynes, entre outros (GONÇALVES, 2011c).

Virginia Woolf frisava que a biografia moderna o poder de gerar conhecimento e de sensibilizar leitores. A desqualificação do que ela e outros, como Harold Nicolson, denominaram de "biografia vitoriana", na alusão às biografias de tom ufanista, em larga medida produzidas ao longo do século XIX, era, em parte, o artifício - muito direcionado para o público leitor inglês, a princípio -, empenhado em demarcar a emergência de uma nova biografia, por meio da defesa de determinado tipo de projeto para escrita biográfica, revendo tanto suas formas, quanto suas funções. Nesse sentido, tal premissa era também sintoma da demanda por uma revisão acerca dos valores e práticas já estabelecidos e consagrados, em especial os que incorriam na comemoração pouco crítica e ao fim, em muitos casos, impregnada por uma pedagogia de tom moralizante.

Na ação de desmonte do "vitorianismo" nas narrativas sobre histórias de sujeitos individuais, a valorização da obra de Lytton Strachey, e em particular, de sua biografia da Rainha Vitória, tornou-se ícone e estratégia de ataque para os que, em outras terras, dialogaram com tais demandas e questões (GONÇALVES, 2011b). André Maurois, por meio de ensaio publicado em 1928 - Aspectos da Biografia -, foi um dos que fez ecoar o debate entre autores ingleses por outras terras. Maurois também considerava a biografia moderna como fruto de mudanças no alvorecer do século $\mathrm{XX}$, atribuindo especial destaque à interferência da psicologia e da ética nos processos de aprendizagem e investigação. Para ele, o biógrafo moderno "seria aquele que entenderia o biografado como uma verdade a ser construída, a partir de um método de investigação pautado no abandono de quaisquer ideias 
pré-concebidas e no levantamento e análise de toda a documentação disponível” (MAUROIS apud GONÇALVES, 2009b, p. 201).

A biografia moderna expandiu-se e consolidou-se firmando-se na oposição à biografia fortemente pautada na exaltação dos feitos do biografado. Luiz Viana Filho, biógrafo que também fez coro com os ventos de renovação da biografia, assim comparou esses dois tipos de biografia:

(...) enquanto a biografia que chamamos histórica, limita os seus próprios objetivos, visando, principalmente, oferecer-nos o perfil histórico duma individualidade, isto é, a narração dos feitos, que lhe asseguram posição de relevo, e coloca em plano secundário o estudo da alma do biografado, a sua vida íntima, os seus motivos, todo o seu mundo interior, a biografia moderna, sem esquecer os seus deveres para com a verdade, tem horizontes mais largos, pois, encarando o biografado como um todo, estuda e expõe todos os aspectos da sua personalidade (VIANA FILHO, 1945, p. 16).

Para Lúcia Miguel Pereira, expor todos os aspectos da personalidade do biografado era busca-lhe o calor da vida, deixar o biografado falar. E era para alcançar esses objetivos que ela se valia não apenas das técnicas do romance, mas também da psicologia, analisando as fontes que citava, lançando questões ao biografado e ao leitor, de forma a tentar preencher as lacunas deixadas pelo tempo e pelos documentos, dotando de significado e de inteligibilidade, por meio da narrativa, a vida que já se esvaíra.

\section{A vida de Gonçalves Dias, uma biografia entre o romance e a história}

"A vida de Gonçalves Dias" não foi o primeiro escrito biográfico de Lúcia Miguel Pereira, antes de se debruçar sobre a vida do poeta maranhense, a autora já havia publicado uma obra de destaque sobre Machado de Assis. Essas obras estão de tal forma interligadas, seja pela construção da narrativa, seja pelo entendimento da autora de que uma era complemento natural da outra, que vale realizar uma breve menção à biografia publicada sobre o "bruxo do Cosme Velho". 
"Machado de Assis: estudo crítico e biográfico" foi publicado em 1936. Toda a argumentação de Lúcia Miguel Pereira, no capítulo inaugural de seu "Machado de Assis", intitulado de "Perspectiva", se pautou na delimitação de abordagem bastante particular, e certamente controversa, para as ambiências da época. Se o sujeito trivial que fora o escritor não deixou, entre as imagens de sua pose oficial, muitos rastros sobre suas vivências íntimas e pessoais, seus livros o traíram e, pelo uso que a biógrafa lhes emprestaria, ao fim, o salvariam. A partir deles, o verdadeiro Machado, sujeito individual contraditório e complexo, poderia ser descoberto. A biógrafa selava com o artistabiografado, e a revelia do mesmo, pacto de vingança maior e inusitada contra o funcionário exemplar e tantas outras personas machadianas construídas de forma, literalmente, lapidar. Desconstrução proposital e pensada, fórmula polêmica, para os termos da época, de subordinar a figuração do biografado às escolhas autorais do biógrafo (GONÇALVES, 2009b).

Lúcia Miguel Pereira fez da escrita biográfica uma experimentação, aquela que ao se afastar da representação de uma trajetória linear de ações cumulativas e satisfatórias, carregou nas tintas da apresentação de vivências variadas, "dos fatos observáveis e ostensivos aos sonhos desfeitos e encontros fortuitos", reunidos em narrativa comprometida com a formação do autor e da obra, essa suposta como sua melhor ação manifesta. (PEREIRA, 1988, p. 23; GONÇALVES, 2009b).

Por meio dessa abordagem biográfica, Lucia Miguel Pereira ofertava ao leitor um novo tipo de biografia, uma biografia onde a narrativa seria pautada pela premissa, naqueles termos, de "fazer viver" e, ao mesmo tempo compreender, seu biografado, nesse caso específico, através das "pistas" deixadas por Machado de Assis em sua obra. Quem está em cena, nessa elaboração narrativa, não é o sujeito précondicionado ou previamente definido, e sim, um sujeito humano fragmentário, com todas as suas dúvidas e inquietações, a constituir-se como autor que veio a ser, à luz de percalços, erros, acertos, incertezas, possibilidades e limitações; era assim, uma busca por apresentar o biografado no máximo de sua condição humana. Lúcia Miguel Pereira afirmava, à sua maneira, o "calor da vida":

A idéia que fazemos dos grandes vultos é, quase sempre, tão diversa da sua personalidade real quanto as estátuas dos homens de carne e osso que foram um dia. Como a estátua, a celebridade fixa o indivíduo em atitudes que podem ter sido 
culminantes, ou características, mas não foram as únicas, nem as habituais. Uma e outra tiram-lhe o movimento, o desalinho, o calor da vida (PEREIRA, 1988, p.11).

Ao querer interpretar seu biografado, e suas idades de vida, numa perspectiva formativa, valendo-se de sua criação literária, Lúcia Miguel Pereira nela identificou dois movimentos opostos e complementares. No seu entendimento, os textos de Machado de Assis foram "evasão" e "transbordamento do eu". Nessa dimensão, guardavam "muito de autobiográfico", não no sentido de narrar literalmente suas vivências, mas como expressão dos sentimentos que as mesmas causaram na alma e no espírito de seu protagonista. Assim, a biógrafa podia coroar sua interpretação biográfica com a bela metáfora de que a obra de Machado de Assis "fora precisamente o avesso da vida". Mais do que lado oposto, "o avesso era o lado de dentro, inseparável do de fora, condicionado por ele" (PEREIRA, 1988, p. 23-24; GONÇALVES, 2009b).

A perspectiva interpretativa construída por Lúcia Miguel Pereira destacou igualmente o valor do drama íntimo de um homem pouco favorecido pelas suas condições existenciais - "inferioridade da educação, impulsos de nevropata, proverbial espevitamento do mestiço" -, a querer impor-se "aos brancos, aos bem-nascidos". Tal drama teria causado em Machado de Assis um movimento instintivo de defesa, corporificado na criação de um personagem, "certo ideal do homem frio, indiferente, impassível” (PEREIRA, 1988: 25).

Ver Machado de Assis como o mestiço, pobre, nevropata era fazer de determinadas contingências o trampolim para possíveis superações, resguardando, nesse tipo de estratégia, a dimensão de um realismo trágico. Em particular, tal premissa manifestou-se na caracterização da nevropatia de seu biografado. Para Lúcia Miguel Pereira esta não foi apenas a sinonímia da epilepsia, mas, no essencial, um conjunto de traços comportamentais derivados desse distúrbio mental, e que fizeram de Machado de Assis um tímido que soube apresentar-se como ousado, distante, altivo (GONÇALVES, 2009a).

Lúcia Miguel Pereira perseguiu a complexidade e as contradições do indivíduo Machado de Assis enquadrando suas idades da vida em um encadeamento que buscava intercalar continuidades e descontinuidades, em especial, quanto à sua formação de letrado e 
escritor. Os títulos dos capítulos corroboram essa orientação, conduzindo o leitor em uma narrativa biográfica ordenada pela mescla de apresentar as identidades personificadas pelo protagonista, ao lado dos momentos diferenciados de elaboração de sua obra como escritor. Sucedem-se, então, as imagens variadas de um mesmo homem constituindo-se pela sobreposição de seus tantos outros - "o moleque, o operário, jornalista, Machadinho, "Seu" Machado, o criador, o artista, o Conselheiro Aires, o escritor e o homem" (PEREIRA, 1988).

Como anunciado por Lúcia Miguel Pereira, a crítica da produção letrada e análise das experiências de vida se interpenetraram em um texto em prosa conciso e direto na emissão de juízos. A biógrafa parecia se inspirar numa das marcas, por muitos apreciada, do texto machadiano. A par dessas questões em mente ela empreendia então uma escrita biográfica onde seu maior objetivo era fazer viver o biografado, destacando suas singularidades, incompletudes e inseguranças e criando um texto onde o leitor poderia se identificar com o personagem retratado.

Após percorrer este caminho na busca por um entendimento de Machado de Assis, Lúcia Miguel Pereira decidiu-se então por (re)conhecer Gonçalves Dias. "A vida de Gonçalves Dias" foi publicado em 1943 pela editora José Olympio como volume integrante da Coleção Documentos Brasileiros, dirigida então por Otávio Tarquínio de Sousa. No prefácio do livro, escrito em dezembro de 1941, Lúcia justificava a obra dizendo que já acalentava o projeto havia cinco anos, pois, depois de escrever sobre Machado de Assis, ficara tentada em "estudar o nosso primeiro grande poeta depois do nosso maior romancista, de unir de algum modo esses dois mestiços admiráveis" (PEREIRA, 1943, p. 05), deixando claro assim, logo no início, que seguiria uma abordagem onde a questão da raça seria crucial em sua interpretação de Gonçalves Dias, como o fora em Machado de Assis.

Lúcia Miguel Pereira demarcava, no entanto, uma diferença no que se referia aos procedimentos de pesquisa para elaborar o seu Gonçalves Dias. Diferentemente do "bruxo do Cosme Velho", que poucos papeis pessoais preservara, Gonçalves Dias, foi mais arquivado, em especial por aqueles que se dispuseram a cuidar de sua memória e de seu legado. Lucia Miguel Pereira pôde consultar não só o arquivo de 
Antonio Henriques Leal ${ }^{5}$, que havia sido recém doado por seu filho, o general Alexandre Leal, ao Instituto Histórico e Geográfico Brasileiro (IHGB), como também o arquivo pessoal de Nogueira da Silva, este último constituindo-se, segundo ela, em mais do que um arquivo de raro valor, mas em um ambiente de culto a Gonçalves Dias (PEREIRA, 1943, p. 6). Lucia Miguel Pereira deixava claro para o leitor que foi sua intenção, desde o início, citar a maior parte dos documentos a que teve acesso, ainda que isso tornasse "pesado" o livro e que por vezes quebrasse a unidade da narrativa. E justificava-se, pois entendera que era o mais correto e até mais honesto, deixando "sempre que possível, falar o próprio Gonçalves Dias” (PEREIRA, 1943, p. 07).

Lúcia Miguel Pereira explicava ainda que, apenas na transcrição do Diário do Rio Negro - inédito até então, resultado da viagem de Gonçalves Dias ao Amazonas, quando da sua participação na Comissão Científica de Exploração e que é apresentado por ela em apêndice à biografia - adotou o critério de resumir ${ }^{6}$. Já no caso do diário da última viagem à Europa, transcrito no "Pantheon Maranhense: ensaios biográficos dos maranhenses ilustres já falecidos" - coletânea de biografias elaborada por Antônio Henriques Leal (1987) -, e que segundo ela, se resumido, perderia muito do valor causado pelas emoções descritas no relato, optou por apresentá-lo na íntegra em meio à narrativa. Valeu-se também das cartas, que por serem numerosas não puderam ser reproduzidas integralmente ${ }^{7}$.

Os cuidados de Lucia Miguel Pereira com a apresentação dos documentos consultados, transcritos e analisados para elaborar sua biografia de Gonçalves Dias denotavam não só uma abordagem diferenciada, em certa medida mais "documentalista", mas especialmente alertavam o leitor acerca da natureza particular da

${ }^{5}$ Amigo de Gonçalves Dias e autor do Pantheon Maranhense, obra onde se encontra a primeira biografia do poeta.

6 Vale ressaltar que Lúcia não foi simplesmente a responsável por levar a conhecimento público este material, foi também a responsável por transcrevê-lo do manuscrito original, escrito a lápis por Gonçalves Dias e em condições que tornam sua leitura um verdadeiro exercício de decifração.

${ }^{7}$ As cartas de Gonçalves Dias foram publicadas nos Anais da Biblioteca Nacional, divididas em correspondência ativa e correspondência passiva, volumes 84 e 91, respectivamente, e reúnem as cartas do poeta que se encontram hoje arquivadas no IHGB, na Biblioteca Nacional e no Museu Imperial. Esse material epistolar, contudo, não sofreu nenhum tipo de estudo no ato de sua publicação, sendo os dois volumes dos Anais apenas a compilação das cartas organizadas em ordem cronológica e com algumas poucas notas explicativas. 
narrativa resultante dessa abordagem, na qual, em alguma medida, os recursos retóricos do romance cediam espaços para os protocolos indicadores das referências e das provas de verdade. Como ela mesma justifica, o leitor poderia ter outros ganhos com sua leitura: "com tantas citações, perdeu certamente o livro aquela coesão estrutural das biografias bem delineadas, mas Gonçalves Dias ficou maior em valor, dominando - e até acachapando, se quiserem - a obra que lhe é consagrada" (PEREIRA, 1943, p. 07).

Os cuidados maiores com os protocolos da pesquisa documental não diminuíram, contudo, o valor da criação literária nos termos híbridos das biografias modernas. Ao analisar a obra podemos perceber que Lúcia Miguel Pereira, como escritora e crítica, sublinhava as interfaces da biografia com a literatura e dessa, por sua vez, com o imaginário. Ação esta que estava de acordo com o movimento da biografia moderna, que, uma vez "humanizando" seus personagens, serviria também como estratégia para a renovação da escrita da história nacional e da história da literatura nacional. Nesse sentido, seu recurso de retratar dois mestiços admiráveis, como ela havia chamado Machado de Assis e Gonçalves Dias, significava dar aos brasileiros de seu tempo dois exemplos em que se espelhar. Era um olhar para o passado que visava estimular os homens do presente (e também do futuro) a superarem suas adversidades. Era o uso da narrativa biográfica como forma de escrita da história e como forma de redimensionar os valores da própria identidade nacional.

Em tempos de sensibilidades modernistas e de reinvenções e redescobrimentos do Brasil, cabia indagar quais deveriam ser os grandes homens que construíram a nação e suas referências identitárias. Para além de deslocar personagens, era fundamental apresentar suas ações e realizações de forma que as mesmas pudessem gerar empatia por esses homens, que tal e qual muitos leitores e leitoras, desejaram, sofreram, superaram adversidades. Nesse ponto, o toque de romance e certos usos da psicologia auxiliavam a biógrafa.

As lacunas deixadas pelos documentos eram preenchidas pelo recurso retórico, pela eloquente interpretação da obra ou pela indagação psicologizante, como na narrativa final dos últimos momentos de vida de Gonçalves Dias: 
Teria o espírito intrépido conservado a lucidez? Teria Gonçalves Dias morrido como desejava como tantas vezes pedira, com o nome de Teófilo e da Amada nos lábios? Não lhes pôde legar o último sorriso, e sua última lágrima, como desejara - mas, se estava em si, legou-lhes certamente o seu último pensamento. Teófilo e Ana Amélia, a amizade e o amor, eram o que de melhor lhe dera a vida. Amando e sofrendo cumprira o seu destino de homem e de poeta (PEREIRA, 1943, p. 381).

Se, por um lado, ao leitor atual tais questões e, principalmente, tais interpretações, às vezes parecem carecer de fundamento e legitimidade, por outro, elas representam o uso das técnicas do romance para preencher silêncios e apagamentos do passado. Elas representam assim, um recurso narrativo para 'dar vida' ao biografado, contextualizando suas obras e realizações nos moldes previstos pela biografia moderna, materializando para esse tipo de escrita a premissa de ser uma forma de criação literária. Segundo Lucia Miguel Pereira, a pesquisa não bastava, pois:

sem sensibilidade para poder se pôr no lugar dos homens do passado, para compreender-lhes a situação, sem espírito de crítica e de síntese para apreender o sentido dos acontecimentos, o ensaio histórico não passará de relatório. Afinal, escrever história, e sobretudo escrevê-la em forma de biografia, pondo em primeiro plano um homem, é uma forma de criação. (...) Se o biógrafo não sofrer, no espírito de quem o estuda, essa verdadeira gestação espiritual, não viverá no livro. As suas ações serão anotadas, mas ele estará ausente. A biografia, ainda quando não tiver nada de romanceada, tem muitos pontos de contatos com o romance (PEREIRA, 1943, p. 189).

Mas é importante destacar que ao aproximar a biografia do romance, Lúcia Miguel Pereira não estava querendo afastá-la da história, ao contrário, buscava alicerçar a biografia nos mesmos pressupostos de verdade exigidos pelo ensaio histórico, livrando-a do "discurso rebarbativo" de que falara Alceu Amoroso Lima, em suas considerações sobre a epidemia biográfica. Aliás, os próprios precursores dessa nova biografia - Strachey, Maurois e Ludwing - não pretendiam afastar a biografia da verdade histórica, apenas transformála numa forma de arte, de criação e não numa ciência, até porque não consideravam a própria história como uma ciência. Nesse sentido, o próprio Lytton Strachey havia afirmado: 
É evidente que a história não é uma ciência. É evidente que a história não é o acumulo de fatos, mas a sua descrição. E os fatos que se referem ao passado, se são reunidos sem arte, são compilações, e as compilações, sem nenhuma dúvida, podem ser úteis, mas não serão história, do mesmo modo que manteiga, ovos, sal e salsa, não são uma omelete (STRACHEY apud VIANA FILHO, 1945, p. 22-23).

Nesse sentido, para Luiz Viana Filho, a dita biografia moderna tomou de empréstimo ao romance apenas aqueles elementos que, longe de lhe serem exclusivos, caberiam em qualquer gênero: "a graça, a leveza, a elegância, a maneira de apresentar o assunto, atraindo a atenção do leitor para o desdobramento da narrativa" (VIANA FILHO, 1945, p.20), justamente aquelas características defendidas e praticadas por Lúcia Miguel Pereira.

Ao contemplar essas características, a biografia seria capaz de despertar o interesse do grande público para a história, tornando mais fluída e atraente a narrativa e sensibilizando o leitor. Lúcia Miguel Pereira, como crítica e biógrafa, sublinhava essa importância, afirmando que era justamente por criar laços sentimentais com o público que a biografia era o melhor meio de se escrever a história e traçava assim a relação da história com a biografia e desta com o romance, formando uma tríade que, no seu entender, era fundamental para produzir o discurso capaz de seduzir o leitor. Ao escrever biografias a par desses critérios, tornava o passado mais presente e, ao escolher com cuidado seus biografados, buscava uma nova história nacional, uma nova identidade, onde história e romance se cruzavam para compreender e valorizar o que ela entendia por "brasileiro" (PEREIRA, 1992, p. 190).

Nesses usos e desdobramentos, a biografia moderna contribuiria para o redimensionamento dos valores da identidade nacional, onde a biografia, enquanto "melhor forma de se fazer história" deveria também edificar a fisionomia nacional (GONÇALVES, 2009a, p. 132). Parece-nos então que, Lúcia Miguel Pereira, por meio de duas biografias - Machado de Assis e Gonçalves Dias - buscou ressaltar a característica miscigenada do país, apresentando-nos dois "mestiços admiráveis", para, ao mesmo tempo, demarcar a singularidade da nação, no que diz respeito ao povo que a constitui e às particularidades destes notáveis, que, como "indivíduos" e "brasileiros", foram apresentados com todas as incompletudes e dilemas que afetam as 
vivências humanas, potencializando assim o grau de identificação do leitor.

No caso particular de Gonçalves Dias, a autora valeu-se da metáfora do "homem de meia cor e meia classe" para caracterizar o filho de pai português e mãe de origem indefinida (não se sabe se índia ou cafuza), fruto de relação ilegítima e por tudo ou, além disso, sem posição social definida. Por meio dessa metáfora, Lucia Miguel Pereira tentar compreender o "estado d'alma" de Gonçalves Dias, e buscar conhecer e decifrar, sua personalidade, apresentando ao leitor muito mais o homem, em sua condição de sujeito fragmentário, do que a obra ou o gênio transcendente.

Por meio dessa perspectiva, Lúcia Miguel Pereira narrou a vida de Gonçalves Dias do nascimento à morte, ressaltando a importância de suas origens familiares e de sua infância. Valorizou, entre outros aspectos, a nota autobiográfica escrita pelo poeta a pedido de Ferdinand Denis, utilizando-a no início do texto, nota na qual Gonçalves Dias relacionava seu ano de nascimento, 1823, à adesão das províncias do norte à independência do Brasil ${ }^{8}$. A biógrafa igualmente destacou adversidades que afetaram Gonçalves Dias na primeira infância, entre elas o sofrimento ao se ver afastado da mãe ainda menino. Ao elaborar narrativa repleta de referências pessoais de Gonçalves Dias, Lucia Miguel Pereira grifava a dimensão mais íntima e pessoal do biografado, por vezes carregando nas tintas ao situar suas dores, angústias, sofrimentos, alegrias e esperanças.

Assim, ao falar da partida de Gonçalves Dias para Coimbra, para onde se dirigiu com o fim de dar prosseguimento aos estudos, Lucia Miguel Pereira pondera que

Ia cumprir o seu destino intelectual, fugindo ao estreito meio em que nascera... e ia também cumprir seu destino de sofredor, enfrentando sozinho a vida, devendo à generosidade alheia o pão que comia, as roupas que vestia, os livros em que estudava,

\footnotetext{
${ }^{8} \mathrm{Na}$ nota em questão Gonçalves Dias escrevera: “As províncias do norte do Brasil foram as que mais tarde aderiram à independência do Império. Caxias, então chamada Aldeias Altas no Maranhão, foi a derradeira. A independência foi ali proclamada depois de uma luta sustentada com denodo por um bravo oficial português que ali se fizera forte. Isto teve lugar à (sic) $1^{\circ}$ de Agosto de 1823. Nasci a 10 de Agosto desse ano.". Esse documento inicia a biografia escrita por Lúcia Miguel Pereira e direciona a narrativa para o estabelecimento da relação entre da vida do poeta com a criação da identidade nacional brasileira.
} 
o jovem Gonçalves Dias, possuidor de seis moleques, de um apaixonado e sofredor temperamento poético, de uma lúcida, positiva inteligência, e de uma imensa, invencível ambição (PEREIRA, 1943, p. 31).

No nosso entendimento, a interpretação de Gonçalves Dias realizada por Lucia Miguel Pereira é profundamente marcada, entre outros aspectos, pelos estudos sociológicos de Gilberto Freyre. As referências a Freyre são relativamente recorrentes. Ao analisar obra poética de Gonçalves Dias, Lucia Miguel Pereira afirmava que "seu indianismo teria de fato o caráter de reação contra a superioridade do branco que o sociólogo do Recife denuncia no Romantismo brasileiro" (PEREIRA, 1943, p. 110). Seguindo este caminho, Lúcia Miguel Pereira estabeleceu ainda a interpretação de que, em sua condição mestiça, Gonçalves Dias identificava-se muito mais com índios ou mesmo aos negros (cuja "influência” em sua origem não é confirmada) do que com português, cujo sangue, segundo ela, ele desprezava.

É com base nesses critérios que a biógrafa analisa, por exemplo, "O canto do índio", poema de Gonçalves Dias datado de 15 de março de 1845, e que para ela é chave para interpretar suas impressões ao retornar a Caxias, no Maranhão, depois dos anos de estudo em Portugal $^{9}$. Naqueles versos, Gonçalves Dias cantou a paixão de um índio por uma mulher branca que ele vira banhando-se em um rio. Para Lúcia, que interpreta o poema como único documento deixado sobre este retorno à sua terra natal, o mesmo poderia ter muitos outros significados:

Não é pois impossível que este tivesse uma origem real, que uma bela banhista descuidada houvesse sido percebida pelo poeta; a indicação do momento em que a viu, o por do sol, não parece apenas fruto de imaginação. E nada mais natural do que deixar-se o poeta, tão sensível aos encantos femininos, empolgar pela visão, e em torno dela tecer todo um poema de amor. O que é estranho, interessante, talvez sintomático, é ter sentido essa mulher branca como se fora um índio. Teria sido o filho de Vicência dominado pelo sangue indígena ao pisar na terra de seus avós? Ter-se-ia sentido índio o moço mestiço, a despeito da cultura coimbrã e do canudo de bacharel? Essa viagem, essa navegação solitária pelo rio que cortava a bravia terra maranhense, ainda tão povoada de índios, era uma tomada de contacto com tanta coisa esquecida, uma volta ao passado,

${ }^{9}$ Gonçalves Dias chegou a Portugal em outubro de 1838 e lá permaneceu até fevereiro de 1845 . 
ao próximo passado da infância, ao longínquo passado da raça. E Gonçalves Dias, subindo o rio numa piroga, reagiu como índio às impressões que o assaltavam (PEREIRA, 1943, p. 56).

A biógrafa buscou igualmente construir explicações para a tristeza e melancolia infindáveis do poeta. Sentimentos que transpareceriam em suas cartas, poemas, diários, e que, em seu entender, era marca indelével de sua personalidade "romântica", compreendendo por romântico, efetivamente, a sua vinculação ao movimento literário do qual hoje ainda é símbolo no que diz respeito à poesia brasileira, marcadamente em sua vertente indianista. A biógrafa encontrou ainda outro motivo, segundo ela condicionado pela reunião de todos os outros fatores - dos preconceitos românticos, da insatisfação de mestiço, da instabilidade social e da saúde precária - e o que marcaria profunda e definitivamente a vida do biografado: a incapacidade de fixar amor em contraste com uma necessidade vital de afeto, de constância na amizade e um profundo horror à solidão. Novamente em uma interpretação psicológica da "alma do biografado" Lucia Miguel Pereira destacava que:

Muito sensível à sedução feminina, Gonçalves Dias correu a vida toda atrás de uma mulher ideal, só tendo sido fiel ao amor que não realizou ${ }^{10}$ - talvez justamente porque o não tenha realizado (PEREIRA, 1943, p. 110).

Parece-nos sintomático que ao escolher aqueles que iria biografar, Lucia Miguel Pereira não tenha se detido em nomes mais consagrados à época em termos dos que se destacaram por façanhas políticas e militares. Ao contrário, tenha se voltado não só para o mundo das letras, mas principalmente para "dois mestiços admiráveis", para dois homens que em suas vidas enfrentaram dificuldades de todas as ordens e, ainda assim, conseguiram construir através de suas obras nomes que eram e são reconhecidos dentro e fora de seu país.

Se considerarmos que, no entender dos intelectuais do início do século $\mathrm{XX}$, as biografias, uma vez que desenhassem as contradições de uma vida individual, em suas mediações sociais e culturais, cumpriam um papel de redescobrimento do homem e do Brasil (PEREIRA, 1943, p.

${ }^{10}$ Lúcia refere-se aqui a Ana Amélia Ferreira do Vale, prima e cunhada de Alexandre Teófilo de Carvalho Leal, melhor amigo do poeta, e por quem ele se apaixonou, mas cujo pedido de casamento feito por ele à mãe da jovem foi recusado, ao que parece, por ser ele um mestiço de origem ilegítima. 
131). Podemos indagar que Lucia Miguel Pereira parecia caminhar no sentido de apresentar o Brasil aos brasileiros, através de dois nomes notáveis sim, mas de notáveis que tinham a particularidade de provirem de origem social humilde e que, narrados e apresentados em suas incompletudes, fragilidades e desafios, serviriam para conquistar e convencer leitores, cumprindo assim a função que Lucia Miguel Pereira havia atribuído à biografia, qual seja: a de fazer com que os brasileiros se interessassem pela história de sua terra, nesse caso, por meio das trajetórias de "dois mestiços admiráveis".

\section{Considerações Finais}

Para Luís Viana Filho, a biografia moderna teria a principal finalidade de proporcionar, em traços vivos e claros, o retrato de um homem considerado sob todos os seus aspectos mais significativos, dimensionando tanto as questões históricas que estivessem associadas ao biografado, quanto os simples atos quotidianos de sua vida, desde que estes fornecessem elementos necessários ao conhecimento da individualidade do personagem. Para ele, na busca por esses elementos, a biografia lançaria mão da história, da crítica e da psicologia, mas sem se subordinar a nenhuma delas, pois encontraria fim em si mesma, na busca por oferecer-nos uma visão de conjunto de uma vida considerada em sua totalidade (VIANA FILHO apud GONÇALVES, 2009a, p. 196).

Em larga medida, foi por meio do diálogo com as ambiências intelectuais e letradas nas quais se formou e se constituiu como autora, e de seu protagonismo como escritora, que Lucia Miguel Pereira delineou sua identidade de biógrafa moderna. Tal identidade, na obra "A vida de Gonçalves Dias", certamente adquiriu um acabamento em maior consonância com o que foi considerado uma nova biografia. Ao apresentar problemas e questionamentos à medida que enfrentava a tarefa de narrar a vida do poeta maranhense, Lúcia Miguel Pereira estabelecia escolhas e interpretações, valendo-se da psicologia, da análise documental e histórica e de sua experiência como crítica literária e estudiosa da literatura brasileira, para fundamentar argumentos e assim tornar compreensíveis as ações, percepções e sentimentos de Gonçalves Dias, construindo narrativa onde a indagação, a dúvida, o "talvez", adquiriam grande valor, 
principalmente ao levar o leitor a se sensibilizar com o biografado. Nesse ponto, o Gonçalves Dias interpretado por Lucia Miguel Pereira, datado e consagrado como texto de referência para aqueles que estudam a obra desse literato, cumpriu a função de contribuir para o desafio de, ao narrar vidas, realizar potencial forma de criação.

\section{Referências}

CORRESPONDENCIA ativa de Gonçalves Dias. Anais da Biblioteca Nacional, Rio de Janeiro, v.84, 1964. (impressão de 1971).

CORRESPONDENCIA passiva de Gonçalves Dias. Anais da Biblioteca Nacional, Rio de Janeiro,v.91, 1971.

DOSSE, François. O desafio biográfico: escrever uma vida. São Paulo: Edusp, 2009.

GONÇALVES, Marcia de Almeida. 2009a; Em terreno movediço: biografia e história na obra de Otávio Tarquínio de Sousa. Rio de Janeiro: EdUERJ.

GONÇALVES, Marcia de Almeida. 2009b; Mestiço, pobre, nevropata: biografia e modernidade no Machado de Assis de Lúcia Miguel Pereira. In: GOMES, Angela de Castro; SCHMIDT, Benito Bisso (Org). Memória e narrativas (auto) biográficas. Rio de Janeiro: FGV.

GONÇALVES, Marcia de Almeida. 2011a; Em tempos de epidemia biográfica: Octávio Tarquínio de Sousa e sua busca por homens históricos. In: Estudos de Historiografia Brasileira / Organizadora Lucia Maria Bastos Pereira das Neves et al. Rio de janeiro: Editora FGV.

GONÇALVES, Marcia de Almeida. 2011b; Aprender com outro? Lições do mundo histórico nas biografias de Octávio Tarquínio de Sousa. In: Aprender com a história?: o passado e o futuro de uma questão / Organizadores: Fernando Nicolazzi, Helena Miranda Mollo, Valdei Lopes de Araújo. Rio de Janeiro: Editora FGV. 
GONÇALVES, Marcia de Almeida. 2011c; História ou romance? A renovação da biografia nas décadas de 1920 a 1940. In: ArtCultura, Uberlândia, v. 13, n. 22, p. 119-135, jan-jun.

LEAL, Antônio Henriques. 1987; Pantheon Maranhense: ensaios biográficos dos maranhenses ilustres já falecidos. Rio de Janeiro: Editorial Alhambra. 2a edição. Tomo 2.

LIMA, Alceu Amoroso. 1931; Biografias. In Estudos. 4ª série. Rio de Janeiro: Edição do Centro Dom Vital.

MADELÉNAT, Daniel. 1984; La biographie. Paris: PUF.

PEREIRA, Lúcia Miguel. 1988; Machado de Assis, estudo crítico e biográfico. S.1.: Círculo Literário Brasileiro.

PEREIRA, Lúcia Miguel. 1988a; Prosa de Ficção (1870-1920). Belo Horizonte: Itatiaia; São Paulo: Editora da Universidade de São Paulo.

PEREIRA, Lúcia Miguel. 1943; A vida de Gonçalves Dias. Rio de Janeiro: José Olympio.

PEREIRA, Lúcia Miguel. 1992; A leitora e seus personagens: seleta de textos publicados em periódicos (1931-1943), e em livros / Lúcia Miguel Pereira; prefácio, Bernardo de Mendonça; pesquisa bibliográfica, seleção e notas, Luciana Viegas. Rio de Janeiro: Graphia Editorial.

VIANA FILHO, Luiz. 1945; A verdade na biografia. Rio de janeiro, São Paulo, Bahia: Ed. Civilização Brasileira.

Recebido em 25/11/2015

Aprovado em 30/12/2015 